\title{
The Current Landscape of Prostitution and Sex Work in England and Wales
}

\author{
Andrea Matolcsi ${ }^{1}$ (D) Natasha Mulvihill ${ }^{1}$ D $\cdot$ Sarah-Jane Lilley-Walker $^{1}$ (D) \\ Alba Lanau $^{1}$ (D) Marianne Hester ${ }^{1}$ (D)
}

Published online: 30 May 2020

(c) The Author(s) 2020

\begin{abstract}
This paper presents a comprehensive typology of the sex industry based on primary data collected between 2018 and 2019 for a UK Home Office-funded study. Typologies of the contemporary sex industry in England and Wales have tended to be limited to particular sectors or have been developed from a specific disciplinary perspective or theme (e.g. sexual health programming, income). Situated in the context of international sex industry typologies, this paper seeks to address this gap. Data was derived from an online survey, questionnaires and consultations with stakeholders including individuals currently or formerly involved in selling sex, service providers/NGOs, police, local authority representatives and others. The data was supplemented with insights from a systematic literature search. This work aims to assist with programme and policy planning in the UK context. Our methods can assist in developing typologies in other contexts.
\end{abstract}

Keywords Sex work $\cdot$ Prostitution $\cdot$ Sex industry $\cdot$ Classification $\cdot$ Typology

\section{Introduction}

A typology of the sex industry can be useful both to understand and distinguish different activities and to assess prevalence, by providing categories within which to count. This can enable the development of targeted services and policies adapted to the specificities and needs of different groups (Buzdugan et al. 2009).

Globally, existing typologies of prostitution and the wider sex industry have been built around different elements, including site of solicitation and/or site of the sexual service; the type of sexual service; whether there is direct physical contact; whether the seller is working independently or there is a third party involved such as

Andrea Matolcsi

andrea.matolcsi@bristol.ac.uk

1 School for Policy Studies, University of Bristol, Bristol, UK 
a pimp, agency or brothel; choice, agency, motivations and life circumstances; and the income earned from selling sexual services.

Some employ a mix of categories. For example, Harcourt and Donovan (2005), in their global typology (detailed below), combine worksite, principal mode of soliciting clients and sexual practices. Sanders and colleagues (2017), also looking worldwide, simplify Harcourt and Donovan's typology and categorise by site or type of sexual service. Brooks-Gordon et al. (2015), focusing on the United Kingdom (UK), use varying combinations of gender, setting/service, income from prostitution/ sex work, working patterns and independent status. Sometimes categorisations are inconsistent across typologies, which means categories will not be mutually exclusive, a feature that Buzdugan et al. (2009) argue is helpful for making typologies suitable for devising programmes and interventions. This is because as long as the typology is 'exhaustive' - another Buzdugan et al. (2009, p. 674) criterion-'then having mutually exclusive categories simplifies the typology without sacrificing the potential for complete programme coverage.'

Often the motivation behind sex industry typologies and categorisations is to inform services and interventions, particularly regarding sexual health; hence categorising by site of solicitation and/or of the sexual service is prominent. Harcourt and Donovan (2005), for example, in seeking to inform health-particularly sexual health-interventions with people selling sexual services, reviewed 681 academic articles related to 'prostitution' identified within Medline, a database of biomedical journal articles. They identified 25 types of prostitution/sex work (they use the terms 'prostitution' and 'sex work' interchangeably), which they divided first into 'direct' and 'indirect'. They describe 'direct' prostitution as 'sexual services widely recognised as "prostitution" because it is clear that the primary purpose of the interaction is to exchange sex for a fee' (p. 201); and 'indirect' prostitution as activities which may not be seen by individuals selling or buying the sexual service as prostitution, and may or may not involve genital contact. Within 'direct' and 'indirect' sex work they divided types according to either worksite, principal mode of soliciting clients or sexual practices, with e.g. street, brothel and escort under 'direct', and e.g. bondage, discipline, lap dancing and 'opportunistic' (occasional, perhaps spur of the moment exchanges of sexual acts for money) under 'indirect'. Belmar et al. (2018) looked at female sex workers in Santiago, Chile with the aim of supporting HIV/ STI programme planning. Based on interviews with service providers and other stakeholders, combined with ethnographic work and observation, they distinguish by venue/location in which the sexual act/service takes place. They identify these to be cafés con piernas (coffee with legs); nightclubs, topless bars and cabarets; brothels; hotels; street and highway soliciting; massage parlours; and private residences. Buzdugan et al. (2010), meanwhile, with the aim of identifying which female sex workers in Karnataka, India are at most risk of contracting HIV, administered faceto-face questionnaires with individuals currently involved in sex work. They devised a typology based on place of both solicitation and the sex act: brothel to brothel, home to home, street to home, street to rented room, street to lodge, street to street.

Many typologies only look at parts of the industry, for example particular types of sexual services. For example, Sloan and Wahab (2004); Colosi (2008) and Bradley-Engen and Ulmer (2009) all present typologies of erotic dance, dancers or clubs, 
while Pitcher (2015a) focuses on 'direct sex work'. Or the focus is on certain groups of sellers, e.g. women only, as done by Belmar et al. (2018) and Buzdugan et al. (2009) above, or men or transgender sellers only, migrants only, and so on. There are also typologies and categorisations of trafficking, including for sexual exploitation, developed for the UK (Cooper et al. 2017) and United States (Polaris Project 2017), and for buyers of sexual services in the UK (Sanders et al. 2009).

Focusing on the UK, Sanders et al. (2018) identify sectors drawing on responses to an online survey, interviews and desk research. Their categories are not limited to online sex work but are limited to data gathered from individuals who advertise and/ or provide sexual services through the internet. They identify the following sectors: Independent/escorting; Agency work; Webcamming; Phone; Brothel; Street; Exotic dance; Adult film; Modelling; Sexual massage; BDSM; Other. Brooks-Gordon et al. (2015), drawing on data from a large sex work project based in London and research on men selling sex, developed a typology within work to measure income generated from prostitution. They delineate the following categories: Female street sex workers (low income); Female street sex workers (migrant); Female off street (middle income); Female off street (high income); Male and Transgender (low income street); Male and Transgender (Occasional independent); Male and Transgender (regular independent); Male and Transgender (high income). Pitcher (2015a), based on a range of data sources and focusing on direct sex work, identifies four categories: street-based sex workers; sex workers in commercial premises (e.g. parlours/ saunas); private/independent/agency workers; and other indoor workers/sector unknown.

Our categorisation:

a. draws on three main sources of data (explained in more detail in the Methods section below):

(i) the experiences of individuals currently/formerly involved in the sex industry

(ii) knowledge from NGOs, police, local authorities, health workers and others

(iii) existing research,

b. aims to look across the entire sex industry in terms of settings and services,

c. includes individuals across genders, nationality, migrant status, and other characteristics,

d. does not approach categorising through a health programming or economic lens.

While there are also underage (under 18 years) individuals involved in various parts of the sex industry, who are victims of child sexual exploitation, the scope of our research and the focus of this typology is limited only to adults (18 years and older) exchanging sexual services for payment or other benefit. 


\section{Methods}

This typology was developed within a study commissioned by the UK Home Office and the Office of the Police and Crime Commissioner for South Wales. The study, on 'The nature and prevalence of prostitution and sex work in England and Wales', was carried out between 2018 and 2019. The 'nature' strand of the work focused on settings and services as presented here and the identification of cross-cutting themes; while the prevalence strand focused on what can be known about the numbers of individuals involved. The research employed a definition of prostitution and sex work as follows: 'the provision of sexual or erotic acts or sexual intimacy in exchange for payment or other benefit or need' (Hester et al. 2019, p. 2). We are conscious of the ideological leanings behind the respective terms 'prostitution' and 'sex work', their limitations and the existence of other terms. We use both in tandem as they are the most widely-recognised, they encompass the wider sex industry (through the use of 'sex work', which includes not only prostitution but also other activities such as webcamming, pornography, lap dance, etc.), and they reflect the range of views on the sex industry and the diverse experiences of those in it. The typology presented here is based on data collected from several sources. First, we looked to the literature from England and Wales, the wider UK, and beyond, to see how typologies have been organised previously and to identify existing knowledge about settings and services. We carried out a systematic literature search of eight key academic databases for social sciences and health, for publications in English from the year 2000 onwards, which included in their abstract the search terms 'prostitut-' or 'sex work' or 'commercial sexual exploitation'. This yielded 10,485 items, after removing duplicates. We added a further 239 items identified via hand search (of e.g. NGO websites) and items recommended by participants through our survey, bringing the total to 10,724 relevant publications. We coded the identified literature by setting or type of service using a grounded approach, using the terms used by authors themselves, and eventually consolidating terms into the most used and mutually exclusive.

Second, we carried out an online survey from June to December 2018, which received 1180 responses, of which 529 (45\%) were from individuals identifying as currently or formerly involved in prostitution and sex work, with remaining respondents representing NGOs/charities, police and other criminal justice practitioners, health workers, academics and students, and a small handful of buyers. Some individuals identified with more than one category. Due to the potential deterrent of asking for too much personal information in a study funded by the Home Office, the agency responsible for law enforcement and immigration in England and Wales, how respondents categorised themselves was the only personal information we asked for. However, many respondents provided demographic and other personal information in other parts of the survey. The survey asked five open-ended questions, including — of relevance here-

- 'Is there any particular study, report or other publication that you think it is important that we pay attention to for this project? Please give details' (Q9); 
- 'Are there particular 'types' of prostitution and sex work that you feel need to be included in this project? Please give details' (Q10); and

- 'Do you have an experience that you think would help us to understand better what prostitution and sex work looks like today in England and Wales? If so, please give details' (Q13).

Responses were downloaded into and analysed using an Excel document. For example, every unique suggestion made in response to the question 'Are there particular 'types' of prostitution and sex work that you feel need to be included in this project?' was recorded. This long list was then analysed and clustered to form a firstcut categorisation.

Similar textual analysis was conducted for responses to Q13 on personal experience. These responses were cross-referred with the emerging categories to check consistency and to elaborate a description for each. To obtain further qualitative description, we sent a follow-up questionnaire by email for self-completion to a subsample of 135 survey respondents (and received 42 completed responses) who identified as being involved currently/formerly in sex work and prostitution, and who reflected a broad range of genders and experiences. Recognising that many individuals involved in the sex industry would not have responded to an online survey, we also sent questionnaires to 76 NGOs working with victims of trafficking and other vulnerable individuals to administer to their service-users or members. We received 16 individual service-user/member responses plus 3 responses completed by NGO staff based on their work with service-users/members generally.

Again, for our follow-up email questionnaires we used open-ended questions and omitted requests for demographic information, in order to be inclusive and to encourage responses. This means that we cannot present data from these diverse sources in simple numerical terms or make, for example, statements on the proportion of respondents involved in certain settings or services, or how many settings or services respondents had been involved in, as we only have information on the settings, services and experiences that respondents chose to discuss. Furthermore, due to the fact that certain groups are less likely to provide information through the survey and questionnaires, including those who have been exploited or traumatised, migrants, individuals who are not proficient in English, and individuals who do not consider themselves to be involved in prostitution/sex work, any numerical conclusions would not have been appropriate.

In the final stage, we cross-referred the categories produced through reviewing the literature with those produced from the online survey and follow-up questionnaire data. Our final consolidated typology therefore documents only those settings and services identified in the literature which are also supported by the data that we collected.

We then organised extensive consultation on this draft typology. In order to cover as much of England and Wales as possible we held four multi-agency consultation events in Bristol, Leeds, London and Cardiff, covering Wales, North East and North West England, Yorkshire and Humberside, South West and South East England, London and the Home Counties. Participants came from the respective regions, representing police and other criminal justice agencies, local governments/councils, 
health organisations/agencies, as well as individuals currently involved in sex work and/or prostitution active in organisations/collectives. Fifty-five individuals from 45 organisations attended overall across the four consultations. We also held 10 individual meetings with NGOs and collectives who worked directly with, or were represented by, individuals currently/formerly involved in sex work and prostitution. This includes organisations primarily made up of or representing individuals currently and formerly involved in sex work and advocating for its decriminalisation, as well as organisations working with those currently and formerly in the sex industry, who seek to raise awareness about exploitation and coercion and advocate for the socalled Nordic model, which criminalises the purchase of sex and decriminalises its sale. Finally, we had ongoing consultation with the academic community via email, telephone and face-to-face meetings and a large academic response $(n=60)$ through the online survey. A first draft of the report was shared with a limited number of stakeholders comprising academics, NGOs and current sex workers, for a 14-day consultation period.

This research was approved by a University of Bristol Research Ethics Committee. For all data collection from individuals, including the survey, questionnaires and consultations, we provided participant information sheets detailing the research, their involvement and confidentiality, and received informed consent.

\section{Results}

Our categorisation comprises two parts. First, we identify six themes which cut across the sex industry as a whole:

- Identifying sex work, identifying as a sex worker;

- Social identities, inequalities and routes in;

- Patterns of engagement and moving between settings/services;

- Advertising, payment and third parties;

- Risk, harm and managing safety;

- Buyers and buying.

These themes both recognise the interconnectedness of the various settings/ services yet also the ways in which they differ, depending on the particular context in which the exchange takes place and on the identities and experiences of the individuals involved. For example, if we take the themes 'risk, harm and managing safety' or 'advertising, payment and third parties': these issues are present for all those involved in selling sex but they will manifest differently and with varying weight, depending on local and individual circumstance. The second part of our categorisation consists of thirteen ${ }^{1}$ settings and services (see Table 1) where sexual or erotic acts or sexual intimacy are exchanged for payment or other benefit or need,

\footnotetext{
1 The study report (Hester et al. 2019) includes a fourteenth setting, 'bar-based sex workand hostess bars'. We have removed this setting from the typology presented here as, while we identified somewhat similar practices in England and Wales, there is no comparablediscrete setting.
} 
Table 1 Settings/services of prostitution and sex work in England and Wales (Hester et al. 2019)

BDSM, kink and fetish

Brothels, massage parlours and saunas operating as brothels

Erotic and exotic dance

Erotic massage

Escorting: independent

Escorting: agency

Pornography, Glamour and Erotica
Sex parties

Street and outdoor

Sugar arrangements

Telephone, text-based, TV-based, Live voyeurism

Therapeutic services

Webcamming

in England and Wales as identified through this research. It is these thirteen settings and services which are the focus of this paper. We present each in turn, drawing primarily on data collected through our survey, questionnaires and consultations. Where literature on a setting or service was identified through our literature search, this is also noted. Please note however that our literature searches did not include terms for each specific setting or service-rather we searched for 'prostitution', 'sex work' and 'commercial sexual exploitation'. Therefore, the absence of literature below on a particular setting or service does not mean it has not been written about in the English or Welsh context.

\section{BDSM, Kink and Fetish}

From our searches, there are minimal academic studies employing ethnographic, survey or interviews concerning the English or Welsh BDSM, kink and fetish scene, although we are aware of some legal and socio-legal commentary (e.g. Cowan 2013). Therefore most of the knowledge for this category was provided by current or recent workers who participated in our study. Our respondents indicated that roles in BDSM (which includes bondage and discipline, dominance and submission, and sadism and masochism), kink or fetish include professional dominant (dominatrix, pro-domme, femdomme); professional submissive (pro-sub; bottom); and professional switch (who may swap roles between dominant and submissive). Dominants are generally female and may provide services online or in-person. There are also male and transgender BDSM practitioners providing services to male, transgender male or female clients. Some BDSM practitioners will state clearly that they offer no intimacy, nudity or genital contact. Escorts and independent workers may also offer some BDSM practices as part of their service.

Practices include spanking, humiliation, roleplay (e.g. as a child, as a pet), bondage, penetration, sado-masochism, play-piercing and other 'impact play'. Many BDSM practitioners will hire a dungeon space or may establish their own. Financial domination (or findom) involves role-playing financial blackmail of the client.

Kink and fetish work can appear non-sexual but the client invests erotic meaning into an object (e.g. shoes) or practice (e.g. trampling), making this a sexual or erotic experience for them. Other services offered within the BDSM, kink and fetish umbrella, as well as by some escorts and independent workers, include hardsports/scat, watersports, sploshing or Adult Nursing Relationship (also known as 'ANR' or erotic lactation). Additional specialist practices described by respondents 
to the online survey include shibari, ropework and session wrestlers. Respondents described the BDSM scene collectively as overwhelmingly White and middle class.

\section{Brothels, Massage Parlours and Saunas Operating as Brothels}

Previous research in England and Wales has looked at the backgrounds and working practices of individuals working in brothel settings (Pitcher 2015a, b, 2019; Sanders et al. 2009; Sanders 2005); their health, including sexual health and drug/alcohol use (Jeal and Salisbury 2007); violence/harm and safety management (Kinnell 2008; Sanders and Campbell 2007; Church et al. 2001); and trafficking and exploitation in brothel settings (Skidmore 2016). These have primarily focused on women in brothel settings, and on residential brothels as well as massage parlours and saunas operating as brothels.

In England and Wales, a brothel is defined as more than one individual providing sexual services from a premises (CPS 2019). Based primarily on our survey responses, we understand brothels as indoor premises where direct sexual services are provided for payment by more than one individual, either simultaneously or at different times. Brothels can exist in residential flats or houses, hotels, and licensed and unlicensed saunas and massage parlours that also offer sexual services (it is important to note that not all massage establishments and saunas offer, or allow on their premises, paid sexual services). We were also told of some nail bars functioning as brothels.

Sexual services offered in brothels include direct sex acts such as penetrative (vaginal or anal) sex, oral sex and manual masturbation. These are sometimes combined with other services such as massage or BDSM.

Brothels can be rented or owned by the individuals (or at least one of the individuals) selling sex from the premises ('collaborative' brothels), or they can be managed by a third party that does not themselves sell sex from the premises, such as a brothel manager, agency, or an individual renting out the premises to those selling sex but not themselves selling sex ('managed brothel').

In managed brothels, (whether in flats, parlours or saunas), individuals work shifts, ranging from e.g. $6 \mathrm{~h}$ to $24 \mathrm{~h}$. They may work anywhere from once per week to 7 days per week. They may work in one brothel or in different brothels over the course of a week/month. Some managed brothels have one individual on-site selling sex at a time, others have several. Managed brothels do their own advertising, and there is usually a receptionist and/or maid who takes bookings/walk-ins and-ideally-screens clients. If there is more than one individual present selling sex, they usually present themselves to the buyer, who chooses an individual, agrees a price either with them or the receptionist/maid, and usually pays this up front and in cash.

Prices in managed brothels depend on the services agreed. Individuals in managed brothels pay a cut to the brothel from what is paid by buyers, usually $40-60 \%$. They may in addition pay further fees to security and the receptionist/maid if this is not included in the initial cut. Some brothels also require people working in them to pay a shift or day fee for being there (one of our respondents reported paying a 
$£ 200$ day fee, plus $20 \%$ of that day's earnings to the receptionist). Individuals may be able to keep money from 'extras', such as sex without a condom or anal sex.

In addition to static managed brothels as described above, in some cases escort agencies or individuals rent out flats to sex workers, and organise clients for them. In cases of trafficking, gangs/traffickers rent out mainly residential premises, including temporarily, keeping predominantly non-UK national victims there to provide sexual services against their will, often moving them between brothels. As recent research shows, traffickers also sometimes exploit women in brothels fronting as 'massage parlours'. These women are sometimes advertised on adult services websites (Skidmore 2016).

In collaborative brothels, individuals selling sex share a flat or house with others selling sex, either concurrently or at different times, taking in-calls as escorts. In some cases, individuals tour together, renting premises temporarily. Aside from a landlord or hotel to whom rent/fees are paid, there is no third party such as an agency or manager involved. Individuals in collaborative brothels usually organise their own advertising and bookings, or they may employ someone else to do so. As recent research notes, in some cases one sex worker takes on an administrative role and charges other workers a fee for rent and other costs, which can blur the lines between managed and collaborative (Pitcher 2015a).

\section{Erotic and Exotic Dance}

Erotic or exotic dance is also known as stripping or striptease. This can take the form of 'strippergrams' or 'kissograms', which involves individuals who are selfemployed or employed via an agency or business to deliver a greeting combined with a striptease act. It can also take the form of lap dancing, pole dancing, table dancing, strip shows, and all are classed as 'relevant entertainment' provided by a Sexual Entertainment Venue as defined in law. Such venues require a license to operate. Burlesque shows may not fall under Sexual Entertainment Venue licensing rules, depending on how they are conducted.

Respondents told us that shifts are arranged through the house manager or agency. There are a wide variety of working conditions and payment methods which dancers identified as frequently problematic, including weak enforcement of the notouching rule and exorbitant management fees. Respondents identified dancers as diverse in terms of socio-economic background and ethnicity.

\section{Erotic Massage}

This service was frequently identified by our survey respondents and email interviewees. Our searches returned no academic literature focused exclusively on this service, although as noted, we did not search for 'erotic massage' specifically. Erotic massage, also known as 'happy ending', 'rub and tug' or 'bodyslide', involves sensual massage ending usually in masturbation of the client. While erotic massage may form part of the repertoire of an escort or independent worker, it can also be offered 
as a distinct service by a dedicated erotic masseur, working with others or alone. Some respondents identified oral sex, rimming (oral stimulation of the anus) or penetration as part of the massage, while others did not. Based on our respondents, erotic massage appears to often be a progression from, or additional practice for, full-service escorts and independent workers.

\section{Escorting: Independent}

The literature on escorting in England and Wales (including studies on the UK as a whole) explores the experiences and backgrounds of both independent and agency escorts, of various genders (Cunningham et al. 2018; Pitcher b, 2019; Sanders et al. 2009 , 2017). Some of the literature focuses on violence and risk/safety management strategies (Kinnell 2008), including specifically by male escorts who sell sex to men (Jamel 2011). There is sometimes differentiation between agency and independent escorts (Pitcher 2015a; Sanders et al. 2016), but not always. The majority of studies appear to focus solely or primarily on independent escorts, including as relates to violence and risk/safety management (Campbell et al. 2019; Davies and Evans 2007).

According to our respondents, those working as independent escorts are independent of third parties such as agencies, managers or pimps. They set their own prices, hours, service limitations and decide which buyers they see. Some may manage all aspects of their work; some may subcontract out aspects such as web design or accounting (see also Pitcher 2015a). They offer direct sexual services, sometimes combined with other services such as BDSM, kink and fetish. They can take in-calls, where they meet clients at their (the escort's) home, a hotel room, or a flat or room rented or owned for this purpose. This can be a static location, or varying locations (e.g. booking hotel rooms while 'touring' different towns/cities). Many would rather share a flat or other premises with others selling sex but avoid doing so because of the risk of arrest under brothel-keeping laws. Independent escorts may also take out-calls, where they meet buyers at the latter's home or at another indoor location organised by the buyer. The majority advertise online, including on adult services websites (including both general and niche websites), social media, dating sites or apps, and/or their own websites. Some advertise on one platform, some on several. Some independent escorts also advertise in local print newspapers, but online was preferred by most of our respondents.

Individuals can have bookings anywhere from every day per week, to only once or twice every few weeks or months. Bookings range from 15 min or half an hour (some escorts will not offer these brief slots), to one or several hours, overnight, or several days. In-calls tend to cost less than out-calls. Additional services such as 'watersports' may cost extra.

Respondents suggested those working as independent escorts are mainly women (cisgender and transgender), and to a lesser extent, men (cisgender and transgender). It has been noted that men, transgender men and transgender women are more likely to work independently than in managed brothel settings (Pitcher 2015a, b). 


\section{Escorting: Agency}

Agency escorts may offer the same services as independent escorts, but will almost always offer out-calls only (for example, meeting a client at a hotel or at the client's home). Agencies will generally organise advertising, booking and handle payment, or workers receive the payment and are asked to refund part of it as commission to the agency.

Key issues raised by agency escort respondents were levels of autonomy and commission charges. Some felt that agencies restricted choice and could make it harder to 'say no'; but this also depended on the agency. Our review of the literature suggests that the majority of the academic studies of escorting in England and Wales focus on independent escorts, or do not make a differentiation between agency and independent.

\section{Pornography, Glamour and Erotica}

Pornography is the depiction (through printed or visual media) of sexual subject matter with the explicit intention of stimulating sexual excitement. The term applies to the depiction, rather than the subject matter itself. So for example, group sex is not pornography, but a photograph depicting group sex could be described as 'pornographic.'

Glamour modelling or photography is a genre of photography involving individuals posing in erotic poses (clothed, part-covered or nude) which can be sold for private use or commercially for calendars and magazines. Erotica refers to works of art or literature which are intended to be sexually stimulating. While distinctions may be made between categories by those involved in the production of pornography, glamour and erotica, consumers may conflate these as 'pornography.'

Respondents identified engaging in the following practices: performing in adult films; glamour photography and modelling; adult or erotic underwear modelling; clip making/clip producing; custom video making; sharing photos/nudes for sale through subscription-based services on mainstream as well as specialist photo-sharing internet sites. A number of respondents referred to engaging in pornography, glamour and erotica in addition to, for example, escorting, BDSM or sugaring. We recognise some overlap with this setting and the Webcamming and Telephone, Text and TV categories below.

\section{Sex Parties}

Sex parties are events where attendees can engage in sexual experiences together in what is positioned as a safe and consenting environment. Respondents both shared experiences of sex parties and a variety of practices under this category were suggested in response to the survey question which asked for suggestions on what our study should include. Parties were variously described as 'sex-positive spaces,' 'play parties,' 'private parties' or 'orgies'. 
Not all of the following examples involve an individual or a group of individuals themselves selling sexual services. For example, for many of the events, attendees may pay an admission price to the organiser, but they do not go on to have sex with the individual organiser. However in some instances, individuals selling sex, such as escorts, are paid to attend or take part in these parties. Escorts accompanying a buyer may or may not be expected to have sex with the buyer or with other individuals at the party. Furthermore, sex workers may also organise parties and provide services.

Drawing on our survey data and the stakeholder consultations, we identified the following examples: swing clubs and swinger parties; party and play; BDSM or kink/fetish play parties; 'elite' or invitation-only sex parties; Weekend events; and dogging. While dogging was originally a term used to describe 'spying' on couples having sex in public (see, e.g. Byrne 2006), it could be considered under the umbrella term 'sex party' since it increasingly involves couple and group sex in public or semi-public places, pre-arranged over the internet. A related practice is a 'gangbang', where a number of individuals have sex with one or more individuals. Gangbangs can be considered as a type of activity in the sex industry insofar as the person with whom multiple individuals are having sex, is paid and is consenting (otherwise, this would constitute gang rape). Aside from at sex parties, gangbangs may also be arranged in brothels and are a feature of some pornography.

\section{Street and Outdoor}

There is a wealth of research by academics and service providers on prostitution taking place on-street/outdoors in England and Wales. These studies have tended to focus on women selling sex in this setting, in particular their physical, sexual and mental health, including drug/alcohol addiction and violence/harm; their social backgrounds; routes in and out; and relationships with intimate partners and children (e.g. O'Neill 2001; Barefoot Research and Evaluation 2016; Renouf 2016; Sandwith 2011; Harding and Hamilton 2009; Sanders et al. 2009; Coy 2008; Jeal et al. 2008; Kinnell 2008; McClelland and Newell 2008; Jeal and Salisbury 2004, 2007; Hester and Westmarland 2004; Church et al. 2001). Fewer have written about men selling sex on-street/outdoors, and how their experiences may differ from female sellers (Ellison 2018; Atkins and Laing 2012; Sanders et al. 2009). Based on information provided by participants in this study, street/outdoor prostitution consists of individuals soliciting to sell sex, or providing sex, in outdoor locations. This is mostly individuals soliciting buyers-e.g. in streets in residential neighbourhoods or in industrial areas, in parks/forests, car/lorry parks, around rail/coach stations or ports-with the sex act also taking place outdoors (including in the buyer's vehicle) or indoors (e.g. in a nearby flat or hotel). However, arrangements can also be made via phone or online, with the sex act taking place outdoors.

Male street prostitution can also take place in cruising sites or gay districts that include other venues such as clubs and bars, where men seek both paid and unpaid sexual encounters with other men (see also Ellison 2018; Atkins and Laing 2012; Sanders et al. 2009). Individuals can stand in an area known for street prostitution 
with buyers coming to these areas, or they can walk around and approach prospective buyers asking for a cigarette or a light, and then offer sexual services. Some individuals solicit in an area alone, others in areas where there are also others selling sex. Respondents noted that peak times for soliciting are usually evenings and mornings, when buyers are going/coming from work, or in the early morning when buyers working night shifts finish work.

The sex acts involved are usually manual masturbation, oral sex, or penetrative (vaginal or anal) sex. Services are normally paid for in cash and up-front. However, sex is also exchanged for shelter, food and drugs/alcohol. In some cases, 'regulars' or buyers who book a hotel room might pay via bank transfer.

Street prostitution mainly involves women (including transgender women) selling sex, but some areas have male street prostitution. Some of these men identify as gay or bisexual, but some identify as heterosexual, although all groups overwhelmingly sell sex to men. We learnt from both individual and agency respondents that while women are more likely to deliberately be on-street for the purpose of selling sex, some men may be cruising for unpaid sex or socialising in gay areas and be solicited for paid sex by older men, and end up selling sex (this is consistent with research by Ellison (2018)).

Many-though not all-street workers have experienced acute circumstances in childhood and adolescence, including abuse and poverty. Later, homelessness or leaving care may facilitate entry into street work. Some respondents self-described or were described by agencies as engaging in 'survival sex' or 'transactional sex' to get by.

\section{Sugar Arrangements}

A sugar arrangement is where one individual enters into what seems to be a mutually beneficial relationship with another, exchanging companionship and/or intimacy with economic security (including fixed monthly payments) or benefit in kind (such as a place to live). Commonly, this will involve a younger woman (a "sugar baby") making an arrangement with an older man (a "sugar daddy"). However, different configurations of gender, including "sugar mamas" and male "sugar babies", as well as same gender relationships, also occur.

Respondents referred to a number of internet sites through which individuals can be introduced and negotiate sugar arrangements. Commonly, sugar parents pay a registration fee and sugar babies do not. A leading sugar arrangement website identifies two-fifths of its registered members as students, a group often looking for support with tuition fees and rent. Our respondents who engaged in sugaring were all young women in their late teens and early $20 \mathrm{~s}$ and identified sugaring as funding study and/or supplementing low-paid work.

While sex is not explicitly identified as part of the arrangement in the online advertising, a number of respondents and the wider academic literature, including from outside the UK, suggest that sex is usually exchanged, even if not initially. Respondents identified this lack of clarity as presenting a significant potential risk. 


\section{Telephone, Text-Based, TV-Based, Live Voyeurism}

This setting includes different forms of technology-enabled sex work, which has increasingly been superseded by the internet. For example, live voyeurism was traditionally provided in the form of peep shows where erotic/pornographic pictures or film, nude or semi-nude models or live sex shows could be viewed from a coin operated booth with shuttered peepholes/viewing windows. While peep shows do still exist in the form of coin-operated booths or windowed cabins (e.g. in London's Soho), live voyeurism now largely operates in the form of webcamming.

Phone sex can be classified as a form of indirect internet-enabled sex work. Most existing phone sex chat services are now integrated with internet services (phone calls to sellers are transferred through the internet-see Sanders et al. 2018). Instant messaging (IM) involves sellers providing sexually explicit photographs or messages via text/SMS to customers on their mobile phones or other electronic devices. A number of adult websites and internet domain services facilitate sex emails and IM services, allowing messages to be sent and received without having to share personal contact information. A number of respondents had tried phone sex, sometimes alongside other types of sex work, but the most common complaint was poor pay. Others talked about the awkwardness of phone encounters, which were often punctuated with silence or ring-offs.

TV phone-ins are interactive adult TV channels which broadcast live simulated sex or sexual conversations and where customers can phone women and men $(18 \mathrm{yrs}+)$ advertised on screen via a premium rate telephone number. The number is often operated free-to-air for a limited period before becoming encrypted so that customers must then subscribe for a fee to gain explicit site access. In recent years, some adult channels have branched out to provide webcam shows alongside these TV enabled phone sex chat lines. None of our respondents referred to adult channel TV work: webcamming was a far more commonly cited (see below).

\section{Therapeutic Services}

We identified one study in England and Wales on therapeutic sexual services, which uses narrative accounts of women engaged in sex work and women engaged in therapeutic massage/bodywork to explore the commonalities between the two areas (Oerton and Phoenix 2001).

According to Limoncin et al. (2014), therapeutic massage can be included within sex work because of the remunerative aspect paired with physical sexual acts (or any activity which involves physical contact and the use of one person by another for her/his sexual satisfaction). Services such as sexual surrogacy, sexual assistance or sexological bodywork offer support to help individuals (mostly, but can also include work with couples or groups) work through any sexual or intimacy problems (see also Wotton and Isbister 2017; Oerton and Phoenix 2001). It can include physical sexual acts such as sexual intercourse, oral sex, massage therapy including erotic massage, masturbatory acts, as well as non-sexual activity such as discussion/ 
education around sexuality, contraception, use of sex toys (Limoncin et al. 2014), immersive role-play, sexual health, gender roles, pleasure and consent.

Respondents suggested that those offering therapeutic services tend to be women working with male clients, but other gender combinations apply. Most work independently and alone (although some do work as part of a couple), are client-led and tend to be educated and usually (but not always) professionally trained/qualified. Relatedly, many of those working as independent sex workers (male and female) receiving clients at home talked about the therapeutic value of their work, particularly in working with individuals with health or disability issues, lack of confidence or internalised shame about their sexuality.

\section{Webcamming}

The 'Beyond the Gaze' project and associated publications by Sanders et al. (2017, 2018) provide key insights into webcamming and contemporary online sex work in England and Wales and the wider UK. It is also a setting our respondents discussed.

Webcamming (also referred to as camming or cam work) involves a 'cammer,' 'cam model' or 'cam worker' using their web camera to sell sexual acts and dialogue, videos and pictures to customers via websites dedicated to hosting webcam shows. Live webcam shows can be public or private and vary in terms of the acts performed (Jones 2016). Usually, nudity or sexual content are streamed to customers watching on their personal computers/tablets/phones (Cunningham et al. 2018). As well as live webcam shows, sellers can also upload pre-recorded videos or photographs that buyers then pay to view.

Customers pay a fee for cam shows via the website/online platform, although some can be accessed for free. Group or public shows are performed to more than one customer and each pays a per-minute rate. Private shows are performed to just one customer and may be priced more highly (Sanders et al. 2017). Some websites operate a system that revolves around 'tips', where a model performs a show in a public 'room' that customers can log into and watch free of charge. The customer then tips the model using tokens purchased from the webcam platforms (Sanders et al. 2017).

Our respondents indicated that cammers tend to set their own prices and work for themselves: many are registered as self-employed and thus pay tax on their earnings. The websites/platforms take a cut of individual earnings and pay the cammer the remainder. The majority of cam workers are women. A common issue cited was needing to earn a certain amount (e.g. £100) before being able to 'check out' your earnings. Camming from home rather than at a commercial venue seemed preferable as cammers had more control to 'switch off' if it became uncomfortable.

\section{Discussion and Conclusions}

We have proposed thirteen settings and services which constitute the current sex industry in England and Wales. Many of these settings and services, including street/ 
outdoor prostitution and brothels, have been identified in previous literature on England and Wales and the wider UK (see e.g. Sanders et al. 2018; Brooks-Gordon et al. 2015), and in other countries (Harcourt and Donovan 2005; Buzdugan et al. 2010; Belmar et al. 2018). Some settings identified in other contexts were not identified in our study, e.g. café's con piernas as identified by Belmar et al. (2018), and 'highway' prostitution as identified in various places including Chile (Belmar et al. 2018) and the United States (Harcourt and Donovan 2005). Some settings/services, such as escorting, webcamming and sugaring, have been identified in this and other studies from the global North, but were not found to feature in studies on the global South.

There are several limitations to our typology. First, we acknowledge that the combination of both setting and service may make it less straightforward for use in service and policy planning. Second, we recognise that some of the categories are broad, incorporating activities with distinctive characteristics, and could therefore be broken down into further categories. Third, we have noted elsewhere the limitations of systematic literature searches (see Mulvihill et al. 2018). Our literature search sought to obtain a broad view of 'prostitution and sex work'. However, since these, together with 'commercial sexual exploitation', constituted our search terms, this limited the literature identified on specific types, particularly those which are not often discussed as prostitution or sex work, e.g. 'sugaring' or pornography. Therefore, further research on particular categories would benefit from re-running these searches using the category as the search term. Fourth, due to time, methodological and ethical constraints, three groups' voices and experiences are underrepresented in our study: migrants, individuals (British and non-British) who have been trafficked, coerced or exploited, and individuals exchanging sex acts for payment or other benefit who do not consider their activity to constitute prostitution or sex work. This means that certain practices or characteristics of settings/services, such as so-called 'survival sex' (TVHG 2008; Barefoot 2016; O’Neill et al. 2017), exchanging sex for rent and exchanging sex for favours within a gang context, are not fully articulated, even if they could fall within categories such as 'independent escorting' or 'street/ outdoor prostitution'.

Finally, we are conscious that the types of prostitution/sex work will vary by geographic location (Buzdugan et al. 2009, 2010), and therefore not every city/town/ rural area will reflect all the settings/services presented in our typology. We are providing an overview across England and Wales as a whole. A future development of this work would be to see how far the categories map to specific locations.

We hope this typology will be of value in planning services and in devising policies in relation to the sex industry in England and Wales. We encourage policymakers and services to be aware of the various settings and services, to ensure that, where required, the differing needs of individuals are met. We also encourage them to be mindful of the breadth of the sex industry, as well as its interconnectedness: our research underscored that individuals are often involved in more than one setting/service over time or concurrently. While we recognise that targeted interventions may be required, we encourage policymakers and law enforcement to be mindful that activity in one area may impact individuals in other areas of the sex industry, in ways which may be beneficial or harmful. 
We also hope that our methods may be of interest to others seeking to develop current typologies in other contexts, particularly similar jurisdictions (e.g. with widespread access to the internet). By drawing on current individual experiences of the sex industry in England and Wales, as well as the existing literature, we reflect the fast-changing nature of contemporary sex markets, which is in turn opening up multiple gaps in our knowledge. We support further, sustained scholarship to explore the intersection of sex, consumption and relations of power and how individuals are negotiating these within shifting welfare and regulatory contexts.

Acknowledgements This work was funded by the UK Home Office and the Office of the Police and Crime Commissioner for South Wales. We are grateful to all who contributed to the research, in particular those with direct experience of selling/exchanging sex.

Funding This work was funded by the UK Home Office and the Office of the Police and Crime Commissioner for South Wales.

\section{Compliance with Ethical Standards}

Conflict of interest The authors declare that they have no conflict of interest.

Ethical Approval This study was approved by a University of Bristol Research Ethics Committee. The Committee is guided by the University of Bristol Research Governance and Integrity Policy, which takes into account the Helsinki declaration among other laws and statutes relevant to the conduct of research, as well as guidance issued by funding, research and other professional bodies. See: http://www.bristol.ac. uk/media-library/sites/red/documents/research-governance/Research\%20Governance\%20and\%20Integrit y\%20Policy\%20V5\%20Approved\%202019.pdf.

Informed Consent Informed consent was obtained from all individual participants included in the study.

Open Access This article is licensed under a Creative Commons Attribution 4.0 International License, which permits use, sharing, adaptation, distribution and reproduction in any medium or format, as long as you give appropriate credit to the original author(s) and the source, provide a link to the Creative Commons licence, and indicate if changes were made. The images or other third party material in this article are included in the article's Creative Commons licence, unless indicated otherwise in a credit line to the material. If material is not included in the article's Creative Commons licence and your intended use is not permitted by statutory regulation or exceeds the permitted use, you will need to obtain permission directly from the copyright holder. To view a copy of this licence, visit http://creativecommons.org/licen ses/by/4.0/.

\section{References}

Atkins, M., \& Laing, M. (2012). Walking the beat and doing business: Exploring spaces of male sex work and public sex. Sexualities, 15(5-6), 622-643.

Barefoot Research and Evaluation (2016). Selling sex for survival: Adult sexual exploitation and prostituti on in the North East and Cumbria. Northern Rock Foundation.

Belmar, J., Stuardo, V., Folch, C., Carvajal, B., Clunes, M. J., Montoliu, A., et al. (2018). A typology of female sex work in the metropolitan region of Santiago, Chile. Culture, Health and Sexuality, 20(4), $428-441$.

Bradley-Engen, M., \& Ulmer, J. (2009). Social worlds of stripping: The processual orders of exotic dance. Sociological Quarterly, 50(1), 29-60. 
Brooks-Gordon, B., Mai, N., Perry, G., \& Sanders, T. (2015). Production, Income, and Expenditure in Commercial Sexual Activity as a Measure of GDP in the UK National Accounts. Report for Office of National Statistics.

Buzdugan, R., Copas, A., Moses, S., Blanchard, J., Isac, S., Ramesh, B. M., et al. (2010). Devising a female sex work typology using data from Karnataka, India. International Journal of Epidemiology, 39(2), 439-448.

Buzdugan, R., Halli, S., \& Cowan, F. M. (2009). The female sex work typology in India in the context of HIV/AIDS. Tropical Medicine and International Health, 14(6), 673-679.

Byrne, R. (2006). Beyond lovers' lane-The rise of illicit sexual leisure in countryside recreational space. Leisure/Loisir, 30(1), 73-85.

Campbell, R., Sanders, T., Scoular, J., Pitcher, J., \& Cunningham, S. (2019). Risking safety and rights: Online Sex work, crimes and 'blended safety repertoires'. British Journal of Sociology, 70(4), a1539-1560.

Church, S., Henderson, M., Barnard, M., \& Hart, G. (2001). Violence by clients towards female prostitutes in different work settings: Questionnaire survey. British Medical Journal, 322(7285), 524-525.

Colosi, R. (2008). Undressing the Moves-An Ethnographic Study of Lap-Dancers and Lap-Dancing Club Culture (Doctoral dissertation). Retrieved from June 2018, https://ethos.bl.uk/OrderDetai 1s.do?uin=uk.bl.ethos.493247.

Cooper, C., Hesketh, O., Ellis, N., \& Fair, A. (2017). A typology of modern slavery offences in the UK. Research Report 93. London: Home Office.

Cowan, S. (2013). To buy or not to buy? Vulnerability and the criminalisation of commercial BDSM. Edinburgh School of Law Research Paper No. 2013/37.

Coy, M. (2008). Young women, local authority care and selling sex: Findings from research. British Journal of Social Work, 38(7), 1408-1424.

Crown Prosecution Service (CPS) (2019). Prostitution and Exploitation of Prostitution. Legal Guidance. Retrieved from September 2019, https://www.cps.gov.uk/legal-guidance/prostitution-and-exploitati on-prostitution.

Cunningham, S., Sanders, T., Scoular, J., Campbell, R., Pitcher, J., Hill, K., et al. (2018). Behind the screen: Commercial sex, digital spaces and working online. Technology in Society, 53, 47-54.

Davies, K., \& Evans, L. (2007). A virtual view of managing violence among british escorts. Deviant Behavior, 28(6), 525-551.

Ellison, G. (2018). Drifters, party boys and incumbents: The life patterns of male street-based sex workers. Sociology, 52(2), 367-383.

Harcourt, C., \& Donovan, B. (2005). The many faces of sex work. Sexually Transmitted Infections, 81(3), 201-206.

Harding, R., \& Hamilton, P. (2009). Working girls: Abuse or choice in street-level sex work? A study of homeless women in Nottingham. British Journal of Social Work, 39(6), 1118-1137.

Hester, M., Mulvihill, N., Matolcsi, A., Lana Sanchez, A., \& Walker, S.-J. (2019). The nature and prevalence of prostitution and sex work in England and wales today. London: Home Office.

Hester, M., \& Westmarland, N. (2004). Tackling street prostitution: Towards an holistic approach. Home Office Research Study 279. London: Home Office.

Jamel, J. (2011). An investigation of the incidence of client- perpetrated sexual violence against male sex workers. International Journal of Sexual Health, 23(1), 63-78.

Jeal, N., \& Salisbury, C. (2004). A health needs assessment of street-based prostitutes: Cross-sectional survey. Journal of Public Health, 26(2), 147-151.

Jeal, N., \& Salisbury, C. (2007). Health needs and service use of parlour-based prostitutes compared with street-based prostitutes: A cross-sectional survey. BJOG An International Journal of Obstetrics and Gynaecology, 114(7), 875-881.

Jeal, N., Salisbury, C., \& Turner, K. (2008). The multiplicity and interdependency of factors influencing the health of street-based sex workers: A qualitative study. Sexually Transmitted Infections, 84, 381-385.

Jones, A. (2016). I get paid to have orgasms: Adult webcam models' negotiation of pleasure and danger. Signs Journal of Women in Culture and Society, 42(1), 227-256.

Kinnell, H. (2008). Violence and sex work in britain. Cullompton: Willan Publishing.

Limoncin, E., Galli, D., Ciocca, G., Gravina, G. L., Carosa, E., Mollaioli, et al. (2014). The psychosexual profile of sexual assistants: An internet-based explorative study. PLOS ONE, 9(6), e98413. 
McClelland, G. T., \& Newell, R. (2008). A qualitative study of the experiences of mothers involved in street-based prostitution and problematic substance USE. Journal of Research in Nursing, 13(5), $437-447$.

Mulvihill, N., Walker, S.-J., Hester, M. \& Gangoli, G. (2018). How is 'justice' understood, sought, and experienced by victims/survivors of gender based violence? A review of the literature.

Oerton, S., \& Phoenix, J. (2001). Sex/bodywork: Discourses and practices. Sexualities, 4(4), 387-412.

O'Neill, M. (2001). Prostitution and feminism: Towards a politics of feeling. Cambridge: Polity Press.

O'Neill, M., Jobe, A., Bilton, C., Stockdale, K., Kath, Hannah, \& Community co-researchers (2017). Peer Talk: hidden stories. A participatory research project with women who sell or swap sex in Teesside. Project Report. A Way Out, Stockton-on-Tees.

Pitcher, J. (2015a). Direct sex work in great britain: Reflecting diversity. Graduate Journal of Social Science, 11(2), 76-100.

Pitcher, J. (2015b). Sex work and modes of self-employment in the informal economy: Diverse business practices and constraints to effective working. Social Policy and Society, 14(1), 113-123.

Pitcher, J. (2019). Intimate labour and the state: Contrasting policy discourses with the working experiences of indoor sex workers. Sexuality Research and Social Policy, 16(2), 138-150.

Polaris Project (2017). The typology of modern slavery defining sex and labor trafficking in the United States.

Renouf, H. (2016). Resettlement experiences of street sex-working women on release from prison. Griffins Society.

Sanders, T. (2005). 'It's just acting': Sex workers' strategies for capitalizing on sexuality. Gender, Work and Organization, 12(4), 319-342.

Sanders, T., \& Campbell, R. (2007). Designing out vulnerability, building in respect: Violence, safety and sex work policy. British Journal of Sociology, 58(1), 1-19.

Sanders, T., Connelly, L. J., \& Jarvis-King, L. (2016). On our own terms: The working conditions of internet-based sex workers in the UK. Sociological Research Online, 21(4), 1-14.

Sanders, T., O'Neill, M., \& Pitcher, J. (2009). Prostitution: Sex work, policy and politics (1st ed.). New York: SAGE Publications Ltd.

Sanders, T., O’Neill, M., \& Pitcher, J. (2017). Prostitution: Sex work, policy and politics (2nd ed.). New York: SAGE Publications Ltd.

Sanders, T., Scoular, J., Campbell, R., Pitcher, J., \& Cunningham, S. (2018). Internet sex work: Beyond the gaze. London: Palgrave Macmillan.

Sandwith, L. (2011). 'Score, smoke, back on the beat'. An exploration of the impact of homelessness on exiting street sex working in Manchester. Griffins Society.

Skidmore, M. (2016). The role and impact of organised crime in the local off-street sex market. Briefing.

Sloan, L., \& Wahab, S. (2004). Four categories of women who work as topless dancers. Sexuality and Culture, 8(1), 18-43.

The Voices Heard Group (TVHG) (2008). Hidden for Survival: Peer Research into the lives of sex workers within Newcastle, Gateshead, Sunderland, South Tyneside and North Tyneside. Research Study TC-02. Newcastle: Tyneside Cyrenians and Counted4.

Wotton, R., \& Isbister, S. (2017). Similarities and differences between sexual surrogacy, sex work and facilitated sexual assistance. The Journal of Sexual Medicine, 14(5), e252-e253.

Publisher's Note Springer Nature remains neutral with regard to jurisdictional claims in published maps and institutional affiliations. 